\title{
The Influence of Teacher Audio Feedback via WeChat Mini Program Sharedaka on Chinese College Students' English Speaking Ability*
}

\author{
Shufen Chen \\ Faculty of International Studies, Henan Normal University, Xinxiang, China
}

\begin{abstract}
In order to effectively improve the English speaking ability of Chinese college students, this paper explores the effectiveness of oral English practice and teacher audio feedback via WeChat Mini Program Sharedaka. The research instruments include a 10-week daka practice, two questionnaires and an interview. It has been found: 1) Oral English practice via Sharedaka has a positive impact on Chinese college students' English speaking ability. 2) Teacher audio feedback better caters to students' need and helps improve their pronunciation and intonation. 3) Communication via Sharedaka creates a more relaxed atmosphere between teachers and students.
\end{abstract}

Index Terms-teacher audio feedback, daka, WeChat Mini Program Sharedaka, Chinese College Students, English speaking ability

\section{INTRODUCTION}

In recent decades, universities in China have been dedicating themselves to reforming teaching modes and methods, shifting from traditional teacher-centered, spoon-feeding and non-individualized teaching to student-centered, interactive and individualized teaching. Great progress has been achieved while problems remain. One especially prominent problem is that many college students are still incapable of communicating their ideas in English, a phenomenon known as mute English.

Exam-oriented education and mass higher education in China are both contributing factors to the mute English phenomenon. On the one hand, though quality education was promoted many years ago, students are still profoundly influenced by the exam-oriented education. The English examination in Gaokao does not attach enough attention to test-takers' speaking and listening abilities, leading to the negligence of these skills by both middle school teachers and students. On the other hand, due to the massified higher education and the large population in China, at present, the student-teacher ratio in many universities is still quite high and many classes are large in size. As a result, students usually do not have enough time and opportunity to practice their English in class. Meanwhile, many college teachers are under heavy workload. Therefore, when students have problems and doubts, where teachers' feedback and help are badly needed, they find it difficult to get timely and effective help and support from teachers.

Teacher feedback has long been recognized as one of the most important aspects of students' learning. According to Bloxham and Boyd (2007), the provision of feedback is "the most important aspect of the assessment process in raising achievement" (p. 20). Researchers in China also identified the importance of teacher feedback, for example, Yuan, Lu and Zhang (2018) claim that proper teacher feedback can facilitate students' emotional development and enhance their learning efficiency and academic performance. However, despite the inarguable importance of teacher feedback, it "has remained one of the least satisfactory areas in students' university experiences" (Xu, 2018, p. 1). Effective feedback should be "timely, precise, thorough and constructive" (Hennessy \& Forrester, 2014, p. 777), otherwise even "the most carefully crafted type" of feedback "could be fated to be misunderstood and ignored" (Mutch, 2003, p. 37).

Against this backdrop, the improvement of teacher feedback effectiveness should still be a critical issue in teaching research. And the study on effective teacher feedback would hopefully provide useful suggestions for enhancing students' English speaking ability.

\section{LITERATURE REVIEW}

\section{A. Feedback}

The significance of feedback has been recognized in motivating learning. Feedback provides information for improvement and enhances students' learning performance, therefore, it is considered by many researchers and teachers to be one of the most powerful ways to strengthen students' learning (Bloxham \& Boyd, 2007; Shute, 2008; Hepplestone et al., 2011). Price et al. (2010) even argue that feedback is "the most important part of the assessment

\footnotetext{
* This research was supported by the Project of Humanity and Social Science Fund of Henan Provincial Education Department (Project No.: 2020-ZDJH-159)
} 
process" (p. 277). Despite its importance, however, feedback is one of the "least understood features in instructional design" (as cited in Shute, 2008, p. 153) and "has remained one of the least satisfactory areas in students' university experiences" (Xu, 2018, p. 1). "Student surveys across the world have highlighted that students are dissatisfied with the feedback they receive on their assignments." (Nicol, 2010, p. 501) The situation is even worse in China due to the constraints of large classes and the high student-teacher ratio.

\section{Written Feedback}

Much research has been carried out on improving written feedback with a focus on the criteria and principles of effective written feedback. Nicol (2011) summarizes good written feedback as understandable, selective, specific, timely, contextualized, non-judgmental, balanced, forward looking, transferable and personal. Based on the review of formative feedback literature, Shute (2008) suggests "formative feedback guidelines for (1) things to do, (2) things to avoid, (3) timing issues, and (4) learner characteristics" (p. 176). Essentially, effective feedback should describe how the student has performed, address problems or errors, explain the goal or standard to reach and provide suggestion on future improvement and should be "timely, detailed and specific" (Gould \& Day, 2013, p. 555).

Of critical importance to effective written feedback are also issues relating to two most important stakeholders, i.e. teachers and students. According to Rust (2002), "explicit guidelines on giving effective feedback" (p. 156) should be provided for teachers. Mutch (2003) points out that feedback should be regarded as a developmental activity instead of focusing just on individual practice. Nicol (2010) proposes that feedback should be considered as "a dialogical and contingent two-way process" because "dialogue is fundamental to successful learning and teaching" (p. 503).

\section{Audio Feedback}

In recent years, there is a growing interest in exploring how technology might be used to support effective feedback. Audio feedback, as a means of facilitating discussions between students and teachers, is considered as an alternative to traditional written feedback (Bond, 2009; Rotheram, 2009; Orsmond et al., 2013; Gould \& Day, 2013; Chew, 2014; Xu, 2018).

Compared with written feedback, audio feedback has several advantages. First, audio feedback is "more detailed, personalized and supportive than written feedback" (Gould \& Day, 2013, p. 554). Second, audio feedback may be more easily accepted and adopted by learners in that it is "more likely to include suggestions for how to improve work, rather than just identifying the problems" (Gould \& Day, 2013, p. 556). Third, audio feedback is less time-consuming than written feedback (Hennessy \& Forrester, 2014) and richer in content in that "one minute of audio is equal to six minutes of writing" (Lunt \& Curran, 2010, p. 761). Fourth, conveying more than "mere words", audio feedback can create "learning conversations" with the help of the teacher's "tone, expression, pronunciation and emphasis", leading to "a greater understanding of tutor/lecturer comments" (Gould \& Day, 2013, p. 556). In the past, restricted by the limitations of information and internet technology, audio feedback was recorded via specific sound-recording software and delivered to students via email or Blackboard, hence lack of attention and wide use.

In Chinese context, studies have also been conducted on teachers' audio feedback. According to a case study of a university English teacher's use of audio feedback on WeChat, a popular social media platform in China, Xu (2018) reveals how the instructor's audio feedback on WeChat increases student engagement and enhances meaning negotiation. Compared with audio feedback in previous researches, using WeChat in giving audio feedback does not require much technical knowledge and is much more user-friendly.

\section{B. WeChat-Assisted English Teaching}

Since its launch on January 21, 2011, WeChat has been developing at a phenomenal speed to be the most popular mobile social software in China, especially among young people. It is an all-in-one messaging app which can be used to send free text and audio messages, pictures and short videos to individual users or in group chat. Files and URLs can also be shared among users. By January 19, 2021, 1.09 billion users used the WeChat app on a daily basis (Zhang, 2021). "WeChat has brought new changes to the user relationship, communication form and communication mode, created a new mobile communication experience" (Jiang, Hou \& Xiong, 2018, p. 584), which has been increasingly used by teachers and students in Chinese universities.

Research on WeChat-assisted English teaching in China mainly falls into three categories: using WeChat as a beneficial extension of classroom teaching, WeChat-based interactive classroom teaching and flipped classes via WeChat (Fan et al., 2015; Miao, 2016). Most studies investigate WeChat functions such as group chat, material sharing and public platforms (Bai \& Hao, 2013; Chai, 2014). Nevertheless, more attention has been paid to utilizing WeChat in enhancing students' reading ability (Jiang, 2016; Chen et al., 2017) while students' listening and speaking abilities are somehow under-researched. The influence of teacher audio feedback via WeChat on improving students' speaking ability has remained relatively under-explored.

\section{We Chat Mini Program Sharedaka}

"WeChat mini programs are 'sub-applications' within the WeChat ecosystem" (Graziani, 2018), providing advanced additional functions to users, such as mobile payment, online shopping, government services, gaming and so on. Without downloading and installing many different apps, users can have access to multimillions of functions within the 
WeChat app. Since its debut on January 1, 2017, there are now more than 3.8 million mini programs, providing service to over 400 million users every day on the WeChat ecosystem ("WeChat Mini Programs Development White Paper", 2021).

One increasingly popular type of WeChat mini program is punch-in, or daka in Chinese. To punch in means "to record the time of one's arrival or beginning work by punching a time clock" (Merriam-Webster Dictionary) and employees are often required to punch in before work and punch out after work. Similarly, such mini programs as Sharedaka allow users to keep a record of their participation in a certain activity.

Sharedaka is a popular WeChat mini program among various others providing free daka services to all WeChat users. It allows users to create their own daka activities or join those created by others. Activities now available on Sharedaka cover different areas such as language learning, reading, sport and exercises, photography and so on. For example, Listening to English Every Morning, a popular activity on Sharedaka, has nearly 180,000 participants. Widely known as the best WeChat mini program for dada activities, it was credited as one of the best WeChat mini programs of education in 2020 and rated among the 100 best WeChat mini programs in 2020 ("WeChat Mini Programs Development White Paper", 2021).

A disproportionate amount of research, however, has exploited the use of WeChat-based daka activities in education and language learning, with focuses mainly on taking the register and creating a reading environment. Wang (2018) used daka activity with her students for one month on their daily progress concerning English vocabulary, listening, reading, translation and writing to make sure they were better prepared for CET-4, an important English test for non-English majors in China. The conclusion was that daka activities can help students, especially those who are lack of self-control, regulate their learning. However, she only required her students to share their progress in group chats and had no effective control over the content, leading to the result that the teacher had to keep the track of students' learning manually and some students lied about their learning progress.

In Xu's (2018) case study on the application of audio feedback on WeChat, though student engagement and meaning negotiation were enhanced, the use of WeChat group chats incurred similar problems. All types of messages or information shared via WeChat group chats are not systematically recorded and it is easy to lose track of them among hundreds of or even thousands of messages. Searching for a particular message might become an arduous task.

In contrast, Sharedaka offers an array of unparalleled advantages. First, there is no restriction on user identity. Anyone can choose to create their own daka activities or join those created by others, without submitting private personal information. Second, different forms are available for the daka content, ranging from text, picture, audio to video. Third, it creates a friendly communication atmosphere, allowing users to view, like or comment on a daka post, or to share it with their friends or on their WeChat moments. Fourth, it provides every participant a personal summary report after an activity ends, helping them to keep track of their own participation and progress. The organizer of an activity can view the reports of all users, which saves the trouble of collecting data manually.

This study thus attempts to explore the use of teacher audio feedback via Sharedaka in the development of college students' English speaking ability, with the hope of providing practical and effective suggestions for both teachers and students in China.

\section{RESEARCH DESIGN}

\section{A. Research Questions}

Based on the purpose of the research, the paper aims to answer the following three questions:

(1) Will daka activity via WeChat Mini Program Sharedaka improve students' English speaking ability?

(2) Will teacher audio feedback via WeChat Mini Program Sharedaka enhance students' English speaking ability?

(3) What are students' perceptions of teacher audio feedback via WeChat Mini Program Sharedaka?

\section{B. Research Subjects}

This small-scale research examines the perceptions of second-year undergraduates who take part in a 10-week oral English practice daka activity and receive teacher feedback in the audio form via WeChat Mini Program Sharedaka. Subjects of the research are 43 students from a natural class taught by the author. Most of them are with relatively lower level of English as they are from an Independent College of a Tier-3 university in China. Timely and additional teacher audio feedback outside class might be more helpful for them compared with students who already excel at oral English.

\section{Research Instruments and Procedures}

This research involves the use of two questionnaires, a 10-week daka activity and a post-daka interview in order to have an in-depth view of the influence of teacher audio feedback on the development of students' English speaking ability. The two questionnaires were conducted via Wenjuanxing, an online questionnaire tool which can automatically generate the results. The interview was recorded and transcribed for closer study.

Before the daka activity, the first questionnaire was conducted to find out students' perceptions of teacher feedback they received in the past and their prior knowledge of WeChat-based daka activities and attitudes towards using them in English learning.

The daka activity via WeChat Mini Program Sharedaka lasted for 10 weeks. All the 43 students were required to post 
their practice of oral English three times a week in either audio or video form. The author reviewed their daka contents and gave at least one audio feedback to every student every week. Peer review was also utilized in the research to ensure the communication among students and to provide them with as much feedback as possible. To guarantee active participation, students' participation in the activity was reflected in their term performance scores.

After the 10-week daka activity, the second questionnaire was used to gather students' thoughts on the activity and teacher audio feedback. In order to better understand the influence of teacher audio feedback on their English speaking ability, eight volunteers were invited to take part in a follow-up interview, which allowed for more personal and detailed reflections.

\section{RESULTS AND DisCUSSIONS}

The study firstly investigated students' perceptions of their own English speaking ability and opinions of teacher feedback. Then the students participated in the 10-week daka practice and received the teacher's feedback on their daka content. After the daka practice, the second questionnaire survey was carried out to gather their reflections, and an interview was organized for more detailed information about their gains and the remaining problems.

\section{A. Pre-daka Student Survey}

The first questionnaire survey aims to investigate students' perceptions of their own oral English, problems in their oral English practice, their need for teacher feedback, and their use of WeChat Mini Program Sharedaka.

\section{Students'Self-Perception}

As shown in Chart I, most of the students are not confident with their own oral English. As for the contributing factors, firstly, many middle school teachers and students fail to attach enough importance to English speaking ability as it is not included in the Gaokao. Secondly, many students are afraid of "losing face" and are unwilling to speak English in front of others unless they think their English is perfect or much better than that of others. Unfortunately, many of them are not satisfied with their own oral English and have very little confidence in speaking English.

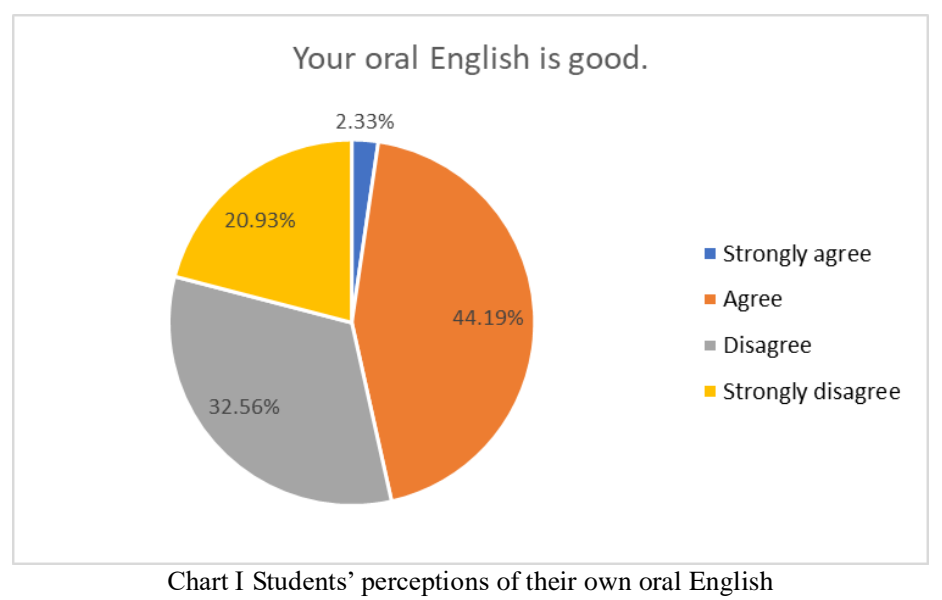

In line with their low self-confidence, $74.42 \%$ of them consider "confidence" to be one of the important factors influencing their English speaking ability (See Table I). Besides, the questionnaire results show the top four influencing factors are their grasp of English grammar, the lack of practice opportunities, vocabulary, and their knowledge about English pronunciation rules.

TABLE I

FACTORS AFFECTING STUDENTS' ENGLISH SPEAKING ABILITY

FACTORS AFFECTING STUDENTS' ENGLISH SPEAKING ABILITY
\begin{tabular}{|l|c|c|}
\hline Item & Number & Percentage \\
\hline Grammar & 36 & $83.72 \%$ \\
\hline Lack of practice opportunities & 36 & $83.72 \%$ \\
\hline Vocabulary & 35 & $81.40 \%$ \\
\hline Lack of knowledge about English pronunciation rules & 34 & $79.07 \%$ \\
\hline Confidence & 32 & $74.42 \%$ \\
\hline Lack of opportunities to communicate with native speakers & 27 & $62.79 \%$ \\
\hline Lack of help from teachers & 20 & $46.51 \%$ \\
\hline Cultural differences & 14 & $32.56 \%$ \\
\hline Lack of help from peers & 13 & $30.23 \%$ \\
\hline Others & 0 & $0.00 \%$ \\
\hline
\end{tabular}

\section{Students' Need for Teacher Feedback}

As analyzed above, though feedback is "the most important part of the assessment process" (Price et al., 2010, p. 
277), it "has remained one of the least satisfactory areas in students' university experiences" (Xu, 2018, p. 1). In the Chinese context, the situation is worse as the result of the large classes and the high student-teacher ratio. University teachers' heavy workload also contributed to the inadequacy of timely teacher feedback. Consequently, though many students are not satisfied with their own oral English, the lack of timely feedback from teachers (See Chart II) finally results in little or fruitless practice of their oral English. As shown in Table I, $46.51 \%$ of the students consider "lack of help from teachers" to have a significant influence on their English speaking ability.

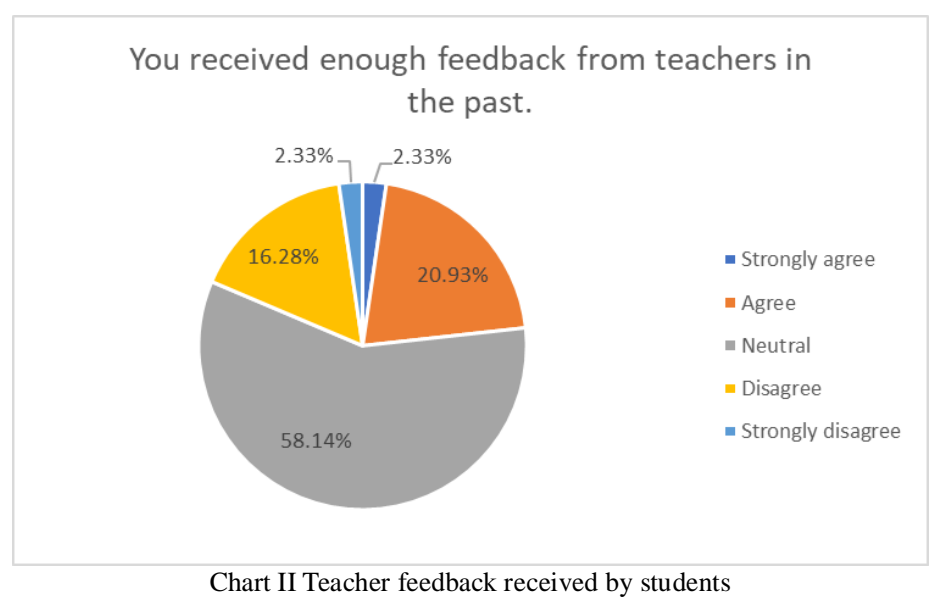

Despite their low self-assurance, all the students are eager to improve their English speaking ability and are in urgent need of guidance and help from teachers (See Chart III).

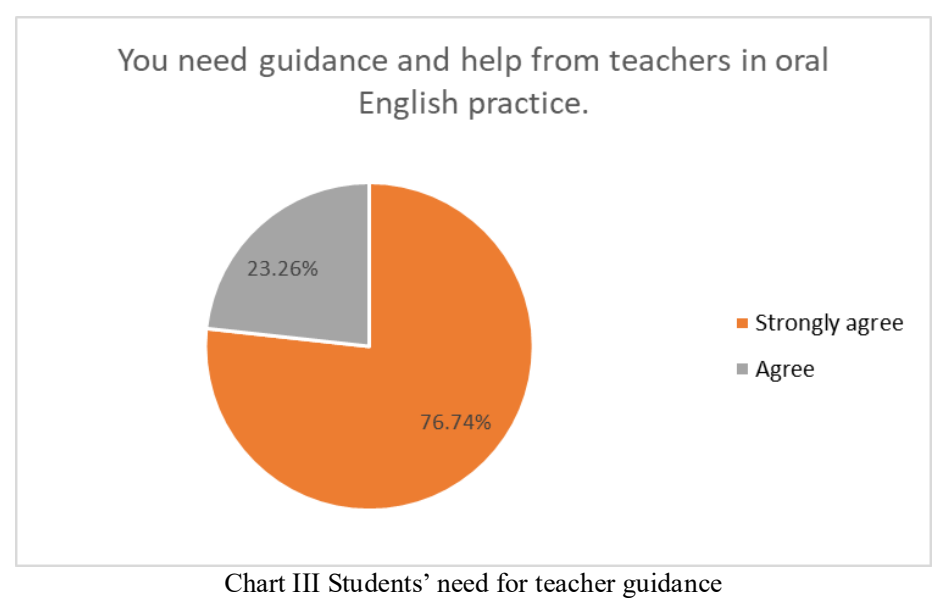

\section{Students' Attitude towards the Daka Activity}

To maximize the effects of oral English practice via Sharedaka, students' familiarity with the mini program and willingness to participate in the daka activity are of vital importance.

In the first place, students' use of smart devices and daka apps are investigated to guarantee their successful participation in the daka activity. Owing to the rapid development of information technology and smartphones, and the popularity of WeChat and WeChat mini programs, all the 43 students have smartphones, with $18.6 \%$ having both a smartphone and a tablet. They all have WeChat accounts and $58.14 \%$ of them are familiar with Sharedaka or similar WeChat mini programs. The author then introduced Sharedaka to those who had no daka experiences.

Also included in the questionnaire is their willingness to participate in the daka activity as this is the prerequisite for their active participation. Since they are eager to improve their own English speaking ability, all of them are therefore willing to participate in the 10 -week daka activity.

\section{B. The Influence of the Daka Activity and Teacher Audio Feedback on Student's English Speaking Ability}

In the 10 -week daka activity via Sharedaka, $79.07 \%$ of the students posted their audio more than 30 times during the activity, meeting the requirement of three times a week (See Chart IV). 


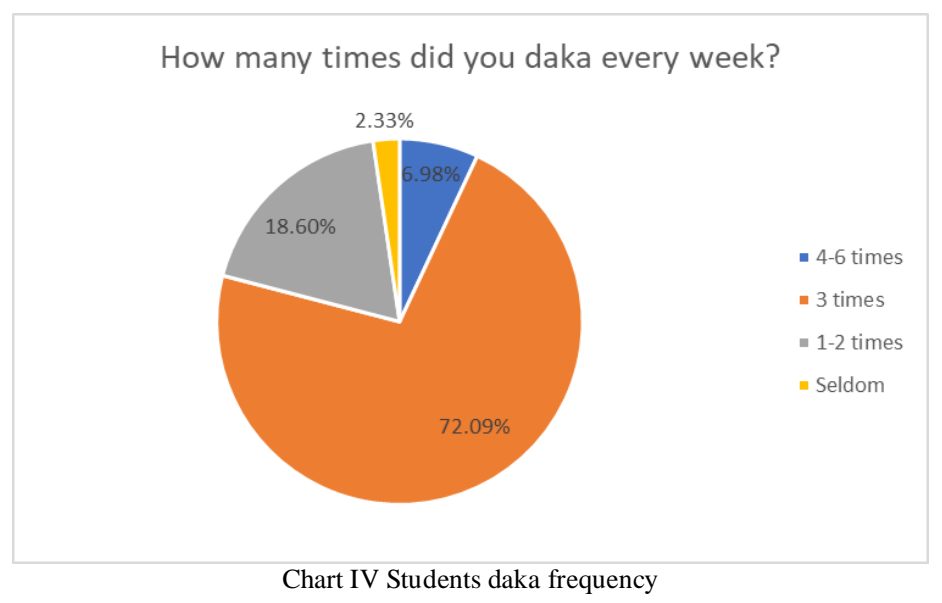

In the 10-week daka activity, the author reviewed students' daka contents and gave at least one audio feedback to every student every week, providing suggestions on their specific problems and general oral English practice. To ensure the communication among students and to provide them with as much feedback as possible, peer review was also utilized in the research, requiring every student to comment on at least three posts every week.

After the daka activity, the second questionnaire survey and follow-up interviews were carried out to gather students' feedback on the use of Sharedaka and teacher audio feedback. The results testify to the positive influence of oral English practice via Sharedaka and of teacher audio feedback on student's English speaking ability.

\section{Improved Accessibility and Convenience}

Limited by the curriculum design, and the number of teachers and classrooms, the students in the research have only two hours' class time for oral English every week and just one teacher, which is still quite common in many universities in China and results in the scarcity of practice opportunities in class. In this context, practice via Sharedaka is not only convenient but free from external constraints such as time, place and weather. With only a smartphone and internet access, students can daka at any time and in any place. According to the post-daka questionnaire, $90.7 \%$ of the students chose to daka at night after a full day's study while this is unlikely in the traditional teaching context.

Moreover, WeChat mini programs allow users to have access to multimillions of functions within WeChat, lowering the threshold for smart devices. With cheap smartphones or tablets, users can still post their practice audio conveniently. Sharedaka provides further help to users in that it can automatically remind them to participate in the chosen activities, which is especially helpful for those who lack self-control.

Moreover, in individual or pair practice, the lack of effective supervision often makes English learners less and less motivated in speaking English. Daka activity, on the contrary, enables learners to monitor each other. Many of them would stick to the end just for the sake of not being left behind. The automatic daily and final reports also help them keep track of their participation and achievements in the daka activity.

\section{Timely and Individualized Feedback}

Chinese university teachers' heavy workload and the high student-teacher ratio pose big obstacles for students to get enough timely feedback and help from teachers, which can seriously undermine students' learning enthusiasm.

Against this backdrop, WeChat Mini Program Sharedaka enables teachers to feedback on each student' oral English practice at any time and in any place. Teacher audio feedback on the one hand provides students more and better help owing to its richer content than written feedback as "one minute of audio is equal to six minutes of writing" (Lunt \& Curran, 2010, p. 761). Giving audio feedback is less time-consuming and thus offers more individualized help on every student's specific problems. On the other hand, conveying more than "mere words", audio feedback creates "learning conversations" with the help of the teacher's "tone, expression, pronunciation and emphasis", leading to "a greater understanding of tutor/lecturer comments" (Gould \& Day, 2013, p. 556). Comments on mistakes or problems are relatively less encouraging than praises. Yet with audio feedback, encouragement can be expressed through the teacher's voice, hence better understanding and acceptance on the part of students.

Furthermore, compared with face-to-face feedback, cloud storage makes audio feedback via Sharedaka accessible to students at any time and in any place. One interviewee said, "I can correct my pronunciation after listening to the teacher's audio feedback but the same mistake might be made again. In that case, I'll listen to the feedback and practice the correct pronunciation again. In this way, I can finally remember the correct pronunciation." Questionnaire results also show that $95.35 \%$ of the students would listen to the author's audio feedback more than once and $97.68 \%$ expected to get similar feedback in the future (See Chart V and Chart VI). 

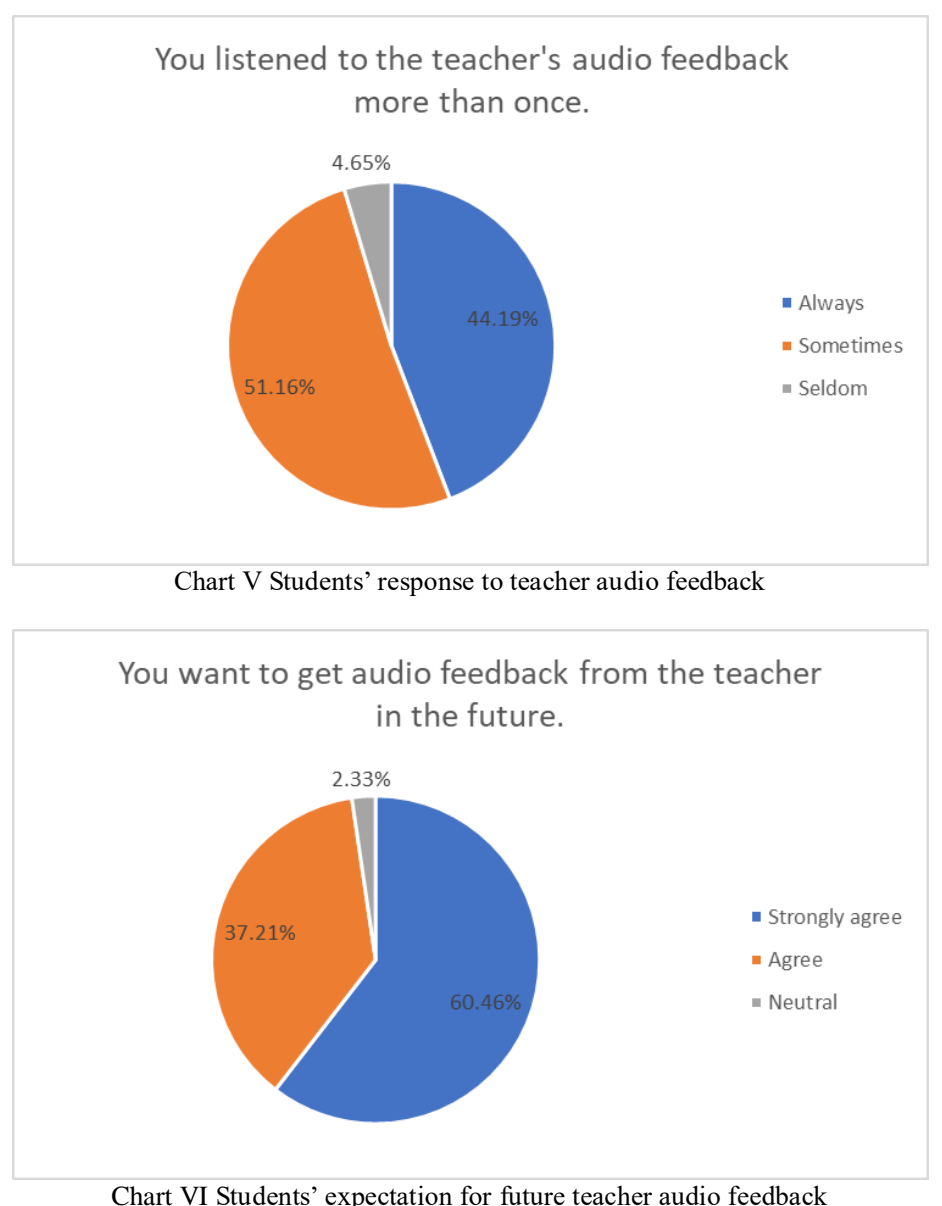

As a result, after the 10-week daka activity, more than $90 \%$ of the students claimed that the daka practice helped improve their pronunciation and English speaking ability (See Chart VII and Chart VIII).

Oral English practice via Sharedaka improves your pronunication.

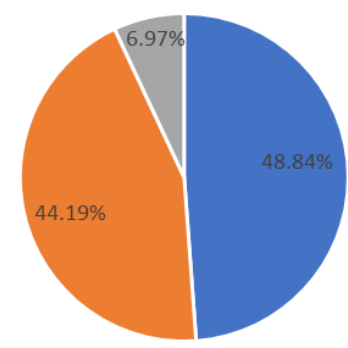

- Strongly agree

agree

Neutral

Chart VII Influence of the daka practice on students' pronunciation 


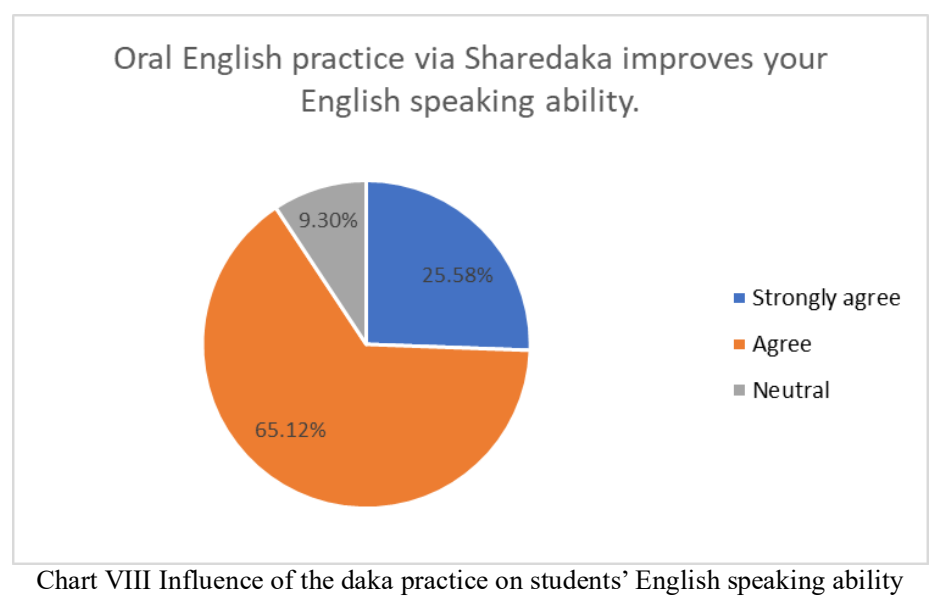

\section{Enhanced Students' Confidence}

Oral English practice via Sharedaka has many advantages over face-to-face communication. First, it minimizes students' shyness and embarrassment. This is especially prominent if they are allowed to use nicknames rather than their real names. One interviewee said, "I'm quite shy and afraid of losing face when speaking English in front of others. But in the daka activity, I could find a quiet place and practice by myself. It's in this way that I can persist in practicing my oral English."

Second, some students would practice many times to perfect their posts, which ensures the practice time. One interviewee gave her comments, "I think my pronunciation and intonation are really very bad so I would often spend almost one hour before I posted my practice. This costs a lot of time but is quite beneficial because it helps me to correct mistakes and makes my pronunciation better."

Third, Sharedaka facilitates students' participation in the activity with the help of the reports on their daka practice. Immediately after each successful daka post, the student receives a report on their ranking in the daka group. Other functions such as giving comments and likes make it easier for all students to communicate with each other and monitor each other's practice. At the same time, they can share their daka posts in WeChat moments or other socializing apps, which further improves their self-confidence through the praises and likes from friends and even strangers. As shown in the two charts below, $88.37 \%$ of the students hope to continue practicing their oral English via Sharedaka.

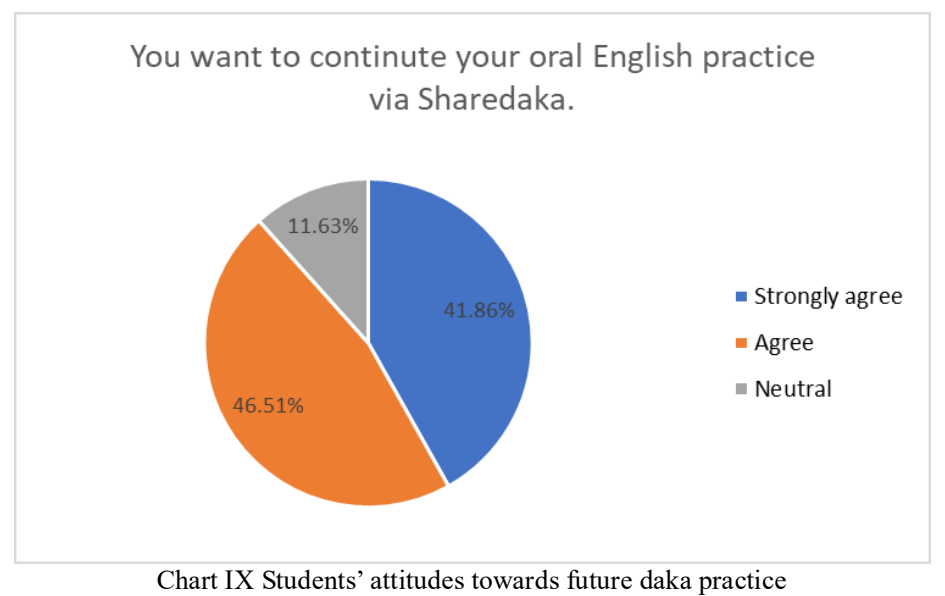

Most importantly, teacher audio feedback via Sharedaka positively increases students' self-assurance. One interviewee expressed her satisfaction by saying, "If I'm praised by the teacher, I'll have a great sense of satisfaction and achievement and will be better motivated to practice speaking English." Even audio feedback on their mistakes can prove to be equally encouraging. Different from the "cold" written feedback, audio feedback from the teacher not only caters to students' specific need, but reduces their uneasiness when receiving comments on their mistakes. They can be assured that making mistakes is inevitable in learning a foreign language and there is no need to worry about losing their faces.

\section{Relaxed Communication Atmosphere}

The daka activity allows the students to practice not only their oral English but also communication skills.

With the help of Sharedaka, every student can view or listen to all the posts in the daka group, give each other comments or encouragement, or help correct each other's mistakes. Since they are required to comment on at least three 
entries every week, many of them would listen to others' posts many times for fear that they would give improper comments. One interviewee expressed her views about giving others comments, "I would be very cautious in commenting on others' posts. If my comments are wrong or I fail to find out their mistakes, I would feel quite guilty. So this not only improves my own English but teaches me to be careful and responsible for every word I said." Another interviewee commented on one of her roommates, "Her oral English is already excellent but she's still quite strict with herself. Every time she would practice her daka content for almost one hour. Besides, she often helped us with our pronunciation by praising our correct pronunciation and pointing out our mistakes. She really helped us a lot."

In addition, the daka activity creates a more relaxed atmosphere for teacher-student communication because it increases the interaction while reducing students' anxiety in face-to-face contact with teachers. The teacher's loaded language and affectionate voice can both elicit a strong positive emotional response from the students. If they have doubts about the teacher's feedback, they can then continue the "conversation" as in real life.

In a word, oral English practice via Sharedaka helps students with not only their pronunciation but mutual communication. Timely communication between the teacher and the students creates a better English learning environment (See Chart X and Chart XI).

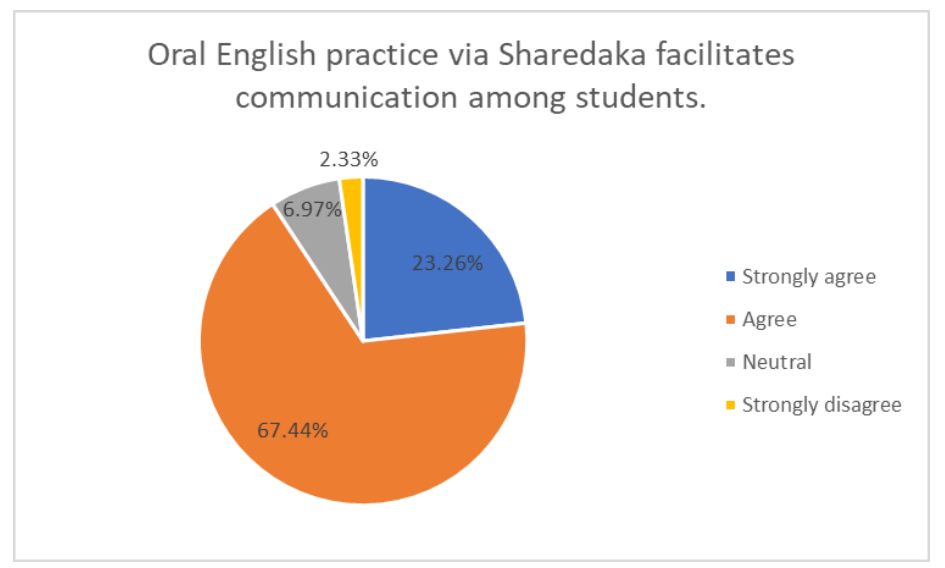

Chart X Influence of the daka activity on communication among students

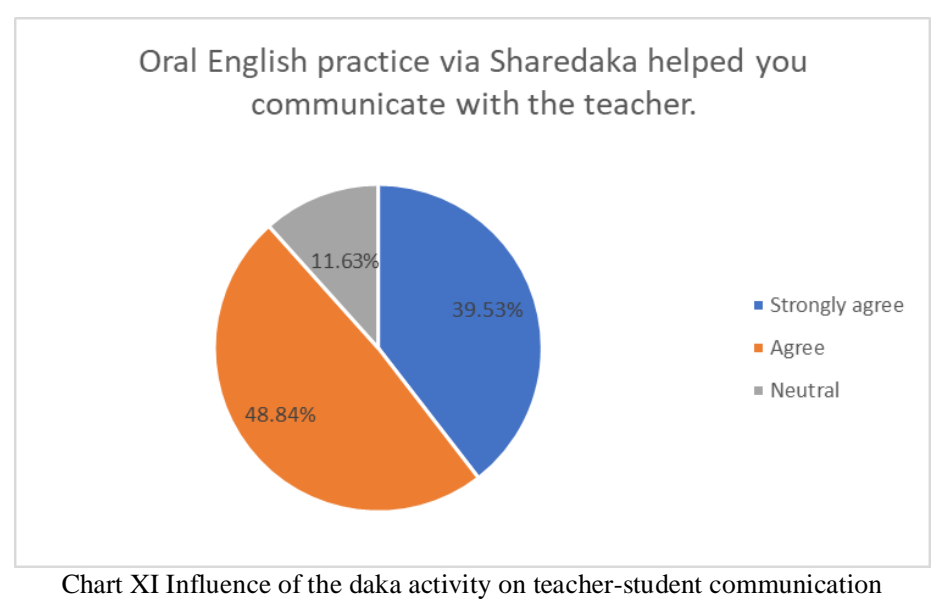

\section{Remaining Problems}

In this study, though the students made great achievements during the daka activity, there are still problems to be solved.

\section{Inadequate Learner Initiative}

The key to any learning is the learner and the realization of learning objectives lies in learner initiative. If learners themselves are not fully aware of the importance of a learning task, the learning results will be negatively influenced. That's the reason why $20.93 \%$ of the students failed to daka three times a week (See Chart IV) in the 10-week daka activity.

Ironically, this is opposite to their perceptions of the effectiveness of practicing speaking English via Sharedaka. Words from one interviewee can explain the reason, "Most of us college students are very lazy and give up practicing English easily." Therefore, teachers should firstly clarify the importance and the requirements of each task and then observe and monitor students' performance closely. Different means of motivation and encouragement are also necessary. 


\section{Learners' Attitudes towards Others' Comments and Criticism}

In the daka activity, besides their own daka practice, the students are also required to give their comments at least three times a week. To fulfill this task, most of the students would listen to others' posts again and again in order to give proper and correct comments. One interviewee said, "I was even more cautious in commenting on others' posts than practicing English myself. I wouldn't give my comments unless I was certain about what I said."

However, some students are unwilling to comment on others' posts out of the following reasons. First, some students just gave their comments for fear of the loss in their term performance scores. As a result, their comments such as "Good pronunciation" and "Well read" were usually monotonous and hollow. Second, some feared that their pronunciation was not good enough for them to give proper comments. Third, some worried that their criticism might incur unfavorable feelings from others.

Since it is almost impossible for a teacher to give each student enough timely feedback, teachers should make sure every student understand the necessity of peer review and help them form correct attitudes towards others' comments.

\section{The Gap between Student Needs and Teacher Capacity}

Among the various factors influencing teacher feedback, the first one concerns the amount of feedback provided. In the 10-week daka activity, the author managed to give every student audio feedback at least once every week, but "one audio feedback every week is far from enough", as commented by one interviewee. This clearly is an inherent problem with teacher feedback. Though compared with traditional written or face-to-face feedback, audio feedback via Sharedaka is more convenient and timely, there is still a great discrepancy between students' needs for teacher feedback and what a teacher can provide. This gap will not be filled unless the high student-teacher ratio can be lowered or teachers' workload can be reduced. Moreover, the motivating force of teacher audio feedback may hinder students' English learning because this is the reason for the active participation of some students. Several interviewees admitted that they would possibly stop daka practice without the teacher's feedback.

Related to the scarcity of teacher feedback is the failure to address students' problems or mistakes in time. One interviewee expressed her idea, "If the teacher didn't give me feedback, I would not know if I had made mistakes and I might continue to pronounce some words in the wrong way." At present all that a teacher could do is take advantage of every chance to communicate with the students. The use of Sharedaka in helping students learn English is a supplementary aid but can never substitute face-to-face communication between teachers and students.

\section{Limitations in the Research Design}

Accurate pronunciation and intonation is only one aspect of speaking English. It is essential and more important for English learners to use appropriate English to express their own ideas and to communicate with others. In the daka activity, however, the students were often trying to demonstrate "perfect" English by practicing the same word or sentence too many times. Some would "spend almost one hour repeating several sentences" in order not to "lose face". The increase in their practice time indeed improves their English speaking ability but causes problems at the same time. On the one hand, it is not real English in real communication situations but just pretentious English as the result of a lot of practice. On the other hand, practicing the daka content many times is only beneficial to the pronunciation of the content itself. Worse still, if the teacher fails to provide timely feedback, the same mistake might be made again and again, resulting in greater difficulty in finally correcting it.

The research results, therefore, prove the positive influence of the daka practice and teacher audio feedback on students' pronunciation and intonation, but there is not enough proof for the improvement of their English speaking ability.

\section{CONCLUSION}

\section{A. Research Findings}

This paper investigated the use of daka activity via WeChat Mini Program Sharedaka in Chinese college students' oral English practice. Besides the analysis of students' performance in the daka activity, it explored the influence of teacher audio feedback via Sharedaka on students.

The results show that both the daka activity and teacher audio feedback via Sharedaka have a positive influence on improving students' English speaking ability. Firstly, the interactivity and convenience of this learning mode has brought great changes to teachers" "teaching" and students' "learning." It lowers the threshold of using technology for both teachers and students and creates a more relaxed communication atmosphere. The relationship between students and teachers and among students themselves can be effectively improved. Secondly, timely and individualized teacher feedback is conducive to improving students' pronunciation and overcoming their anxiety when speaking English. With more opportunities for oral English practice and more feedback on their specific problems, their learning readiness is significantly motivated. Thirdly, it is helpful to build students' sense of accomplishment and fulfillment. Teachers' affirmation has a significant effect on enhancing students' self-confidence, which in turn results in the development of their English speaking ability.

However, several problems arose in the research. The first concerns students' self-control. Students who lack self-control are unable to persist in practicing speaking English despite their willingness to participate in the daka 
activity. What follows is their attitudes towards giving comments. Their reluctance to comment on others' posts is caused by either fears for "improper" comments they might give or unfavorable opinions of the receiver. The most prominent problem lies in the gap between students' needs and teachers' capacity. In the Chinese context, this is very difficult to solve unless the high student-teacher ratio can be lowered or teachers' workload can be reduced.

\section{B. Pedagogical Implications}

English speaking ability has long been a headache for many Chinese English learners. The improvement of their oral English attracts attention from not only students themselves but also teachers and researchers. Though great achievements have been made, the mute English phenomenon still exists and many Chinese English learners are still afraid of speaking English in front of others.

In this context, it is of primal importance for teachers to cater to the learning needs of students, and constantly utilize new teaching methods to create a disciplined and relaxed classroom atmosphere. This paper proves the positive influence of the daka activity via Sharedaka on students' English speaking ability. The research result can help teachers and students to better make use of the convenience of the information age and the internet technology. In the context of the information age, the use of smart devices and mobile apps can not only improve teaching quality, but also stimulate students' initiative in English learning. WeChat, with its many communicational characteristics, can effectively promote the exchange between teachers and students, leading to more than better understanding and emotional communication.

Meanwhile, teachers should reflect on their use of teaching resources and methods. Instead of fearing for the distraction from smart devices, teachers should develop an impartial attitude towards their use in teaching and learning. It will be better for teachers to provide guidance on students' use of the smartphone instead of simply forbidding its use.

Lastly, it is worth noting that the smart devices and mobile apps are created to serve teaching and learning needs not to take the place of real-life interaction. In exploiting the use of tools like WeChat and WeChat mini programs, face-to-face communication between teachers and students should never be neglected.

\section{REFERENCES}

[1] Bai Hao. \& Hao Jingjing. (2013). Application Research of WeChat Public Platforms in Higher Education. The Chinese Journal of ICT in Education, (4): 78-81.

[2] Bloxham, S., \& Boyd, P. (2007). Developing Effective Assessment in Higher Education: A Practical Guide. Maidenhead: Open University Press.

[3] Bond, S. (2009). Audio Feedback. Centre for Learning Technology, London School of Economics and Political Science, London, UK. (Submitted)

[4] Chai Yangli. (2014). The Survey Research on the Current Situation and the WeChat Requirements of the English Audio-visual Teaching. Technology Enhanced Foreign Language Education, (5): 34-39.

[5] Chen Hang., Xu Caiyu. \& Wang Yuefen. (2017). A Study on the Characteristics and Influencing Factors of Fragmented Information Reading Behavior in WeChat. Library \& Information, (3): 26-35.

[6] Chew, E. (2014). “To Listen or to Read?" Audio or Written Assessment Feedback for International Students in the UK. On the Horizon, 22(2): 127-135.

[7] Fan Wenxiang., Ma Yan., Li Kai., \& Qiu Bingfa. (2015). A Practical Study in the Flipped Classroom Based on WeChat under Environment of Mobile Learning. Open Education Research, 21(3): 90-97.

[8] Gould, J., \& Day, P. (2013). Hearing You Loud and Clear: Student Perspectives of Audio Feedback in Higher Education. Assessment \& Evaluation in Higher Education, 38(5): 554-566.

[9] Graziani, T. (2018, October 6). What Are WeChat Mini-Programs? A Simple Introduction. Retrieved August 11, 2021, from: https://walkthechat.com/wechat-mini-programs-simple-introduction.

[10] Hennessy, C., \& Forrester, G. (2014). Developing a Framework for Effective Audio Feedback: A Case Study. Assessment \& Evaluation in Higher Education, 39(7): 777-789.

[11] Hepplestone, S., Holden, G., Irwin, B., Parkin, H. J., \& Thorpe, L. (2011). Using Technology to Encourage Student Engagement with Feedback: A Literature Review. Research in Learning Technology, 19(2): 117-127.

[12] Jiang Jie, Hou Yuan, \& Xiong Zhen. (2018). Analysis of Mobile Learning Function and Design Principles Based on WeChat. 2018 13th International Conference on Computer Science \& Education (ICCSE). IEEE, 584-587.

[13] Jiang Yinjian. (2016). An Experimental Study on English Reading Teaching Supported by WeChat Public Platform. Technology Enhanced Foreign Language Education, (3): 58-63.

[14] Lunt, T., \& Curran, J. (2010). 'Are You Listening Please?' The Advantages of Electronic Audio Feedback Compared to Written Feedback. Assessment \& Evaluation in Higher Education, 35(7): 759-769.

[15] Miao Ning. (2016). English Mobile Learning Strategies in Universities and Colleges Based on WeChat. China Educational Technology, (3): 136-140.

[16] Mutch, A. (2003). Exploring the Practice of Feedback to Students. Active Learning in Higher Education, 4(1): 24-38.

[17] Nicol, D. (2010). From Monologue to Dialogue: Improving Written Feedback Processes in Mass Higher Education. Assessment \& Evaluation in Higher Education, 35(5): 501-517.

[18] Nicol, D. (2011). Good Designs for Written Feedback for Students. In M. Svinicki \& W. J. McKeachie (eds), McKeachie’s Teaching Tips: Strategies, Research and Theory for College and University Teachers (13th ed.) (pp. 108-124). Belmont: Wadsworth Publishing.

[19] Orsmond, P., Maw, S. J., Park, J. R., Gomez, S., \& Crook, A. C. (2013). Moving Feedback Forward: Theory to Practice. Assessment \& Evaluation in Higher Education, 38(2): 240-252.

[20] Price, M., Handley, K., Millar, J., \& O’Donovan, B. (2010). Feedback: All That Effort, but What Is the Effect?. Assessment \& 
Evaluation in Higher Education, 35(3): 277-289.

[21] Rotheram, B. (2009). Sounds Good: Using Digital Audio for Evaluation Feedback. Collected Essays on Learning and Teaching, (2): 176-179.

[22] Rust, C. (2002). The Impact of Assessment on Student Learning: How Can the Research Literature Practically Help to Inform the Development of Departmental Assessment Strategies and Learner-centred Assessment Practices?. Active Learning in Higher Education, 3(2): 145-158.

[23] Shute, V. J. (2008). Focus on Formative Feedback. Review of Educational Research, 78(1): 153-189.

[24] Wang Yansu. (2018). Influence of the Daka Mechanism on Motivating College Students' English Learning for Exams. Technology and Economic Guide, 26(13): 137-138.

[25] WeChat Mini Programs Development White Paper. (2021, January 13). Retrieved August 11, 2021, from: https://aldzs.com/viewpointarticle?id=14552.

[26] Xu Yueting. (2018). Not Just Listening to the Teacher's Voice: A Case Study of a University English Teacher's Use of Audio Feedback on Social Media in China. Frontiers in Education, Volume 3, Article 65. Retrieved September 13, 2021, from: https://doi.org/10.3389/feduc.2018.00065.

[27] Yuan Zhaohui., Lu Jingjing., \& Zhang Rui. (2018). A Social Constructionist Study on the Influence of Teacher Verbal Feedback on Students' Positive Affect. New West, (36): 35-36+29.

[28] Zhang Xiaolong. (2021). Deep Thinking on the Next 10 Years of WeChat. Retrieved August 11, 2021, from: https://mp.weixin.qq.com/s/LwkXAhTHx3fkToQMsy51Dg.

Shufen Chen was born in Xuchang, China in 1976. She received her MA degree in English Language and Literature from Henan Normal University, China in 2007.

She is currently a lecturer in the Faculty of International Studies, Henan Normal University, Xinxiang, China. Her research interests include English language teaching and applied linguistics. 